\title{
BUILDING A MORE EQUITABLE SOCIETY, THROUGH INCLUSIVE EDUCATION AND THE SUCESFULL TEACHER WORK
}

\author{
DORINA QIRJAKO GJIKOKA
}

"Deparment of English Languages, Albania

Teacher of English Language, Vlora Albania

\section{ABSTRACT:}

If the right to education for all is to become a reality, all learners must have access to quality education that meets basic learning needs and enriches lives. The UNESCO Convention against Discrimination in Education (1960) and other international human rights treaties prohibit any exclusion from or limitation to educational opportunities on the basis of socially ascribed or perceived differences, such as gender, sexuality, ethnicity, language, religion, nationality, economic condition and/or ability.

Education should not be simply about making schools available for those who are already able to access them. Instead, it is about being proactive in identifying the barriers and obstacles learners encounter in attempting to access equal opportunities for quality education, as well as in removing those barriers and obstacles that lead 49 to marginalization and exclusion. Education systems should be made inclusive and equitable; that is, every child and young person should have access to education that is welcoming and responsive to his or her characteristics and needs (UNESCO, 2012)

Monitoring student progress with learning trackers (observation logs, observation forms, conferring logs, etc.) provides the teacher with data, e.g., the degree to which the student has mastered a learning target, who needs retouching, who needs additional challenges, what the next learning target should be, how students should be grouped for small-group instruction, and who needs to be observed more closely for a possible learning intervention. The existing research does indicate, however, that well-designed classroom testing programs bear a positive relationship to later student achievement.

Key words: Albanian reforms, teacher working plan, Take Time to Reflect, Albanian language, Education directories, Practice, exams, working class, Teacher training, School documentation, Children, Class, School program, Performance, Educational teacher roles.

JEL Classification System: N1, N3,SI, S2, S3, N0, N1, N2, N3, O1, O2, 03 


\section{GENERAL INFORMATION AND PURPOSE OF THIS PAPER RESEARCH:} Evaluate experience and Teaching analysis:

Analysis across the three policy domains clearly demonstrates that social and educational inclusion is a systemic issue worthy of greater attention in Albania. The analysis showed that Albania has made progress towards achieving universal primary school enrolment and increased access to all levels of education. However, the Government should pay particular attention when it comes to the enrolment rates of national minorities as well as children with disabilities.Source: Collen 2017

Despite previous efforts to integrate children with disabilities and special needs into mainstream education in Albania, the development of inclusive education as described in this EPR is still only partially realized. Several of the policy issues and recommendations elaborated in each of the domains have illuminated areas where greater steps towards equity and inclusion can be taken.Beneficial effects are noted when tests are: Administered regularly and frequently An integral part of the instructional approach (i.e., well-aligned with the material being taught) Collected, scored, recorded and returned to students promptly so that they can correct errors of understanding before these become ingrained

Definitions of Formative Assessments \& Monitoring Student Progress Formative Assessment the intentional and systematic process used by teachers and students during instruction that provides immediate feedback to adjust on-going teaching and learning in order to improve students' achievement of the intended instructional outcomes. Monitoring Student Progress

Source: DFA Monitoring Student Progress 2017

\section{LITERATURE REVIEW AND HYPOTHESES}

The Government of Albania provides leadership and investment, to emphasize in the curriculum that social inclusion and social cohesion are major aims for the society. The Government should also ensure the universal nature of public education that extends equally to all regions, localities and social classes. In order to ensure full inclusion, there is a need for a more rigorous and complete compilation of data on student enrolment and/ or achievement. In addition, there is a need for education and training in inclusive pedagogies to be added to the initial teacher education (ITE) programmers. Source: DFA Monitoring Student Progress 2017

Meaningful information can come with purposely designed and systematically used learning trackers which are then used to make decisions about student placement and instructional pacing. "Effective teachers see things. They file those things away. They accumulate evidence of 
proficiency. They know their students. No other assessor of student achievement has the opportunity to see students like this over time.

Those who study assessment and evaluation techniques are quick to point out that the role of standardized testing has received considerably more research attention than have classroom testing and other classroom-level assessment methods.

1. When educators speak of classroom monitoring, they generally refer to the following teacher behaviors:

2. Questioning students during classroom discussions to check their understanding of the material being taught

3. Circulating around the classroom during seatwork and engaging in one-to-one contacts with students about their work Assigning, collecting, and correcting homework; recording completion and grades

4. Conducting periodic reviews with students to confirm their grasp of learning material and identify gaps in their knowledge and understanding Administering and correcting tests; recording scores

5. Reviewing student performance data collected and recorded and using these data to make needed adjustments in instruction

6. Defined this way, monitoring obviously includes many kinds of activities, but it is important to note that the present analysis does not address issues relating to school wide or district-level monitoring of student learning.

7. It is not concerned, except incidentally, with monitoring students' behavior.

8. And it provides only cursory information on such matters as teacher training in monitoring and assessment practices or the processes teachers follow in putting monitoring information to use.

9. Instead, the focus here is classroom-level monitoring of student learning progress and what research says about the relationships between such monitoring and the student outcomes of achievement, attitudes and social behavior.

\subsection{INTRODUCTION}

Measure Progress with Documentation in class

Systematically develop short surveys for teachers, principals, and regional education directors to be administered annually with the intention of identifying successful practices, unexpected issues, obstacles and successes with implementation. The term "learning probe" refers to a variety of ways that teachers can ask for brief student responses to lesson content so as to determine their understanding of what is being taught.

Questions to the class, quizzes, and other means of calling upon students to demonstrate their understanding are methods used by teachers to find out if their instruction is "working" or if it needs to be adjusted in some way. Source: DFA Monitoring Student Progress 2017

Does the use of learning probes have a beneficial effect on student achievement? 
1. Implement the Higher Education Reform, with a particular focus on the education of candidate teachers, and develop a national system to monitor the ongoing development of pre- and in-service teachers' ICT skills.

2. As part of, or in addition to, the training underway for the new curriculum, engage in a process of collaborative inquiry at the school level that assists teachers and principals in developing a repertoire of high level pedagogical and assessment skills required for the implementation of both the curriculum and effective inclusion practices

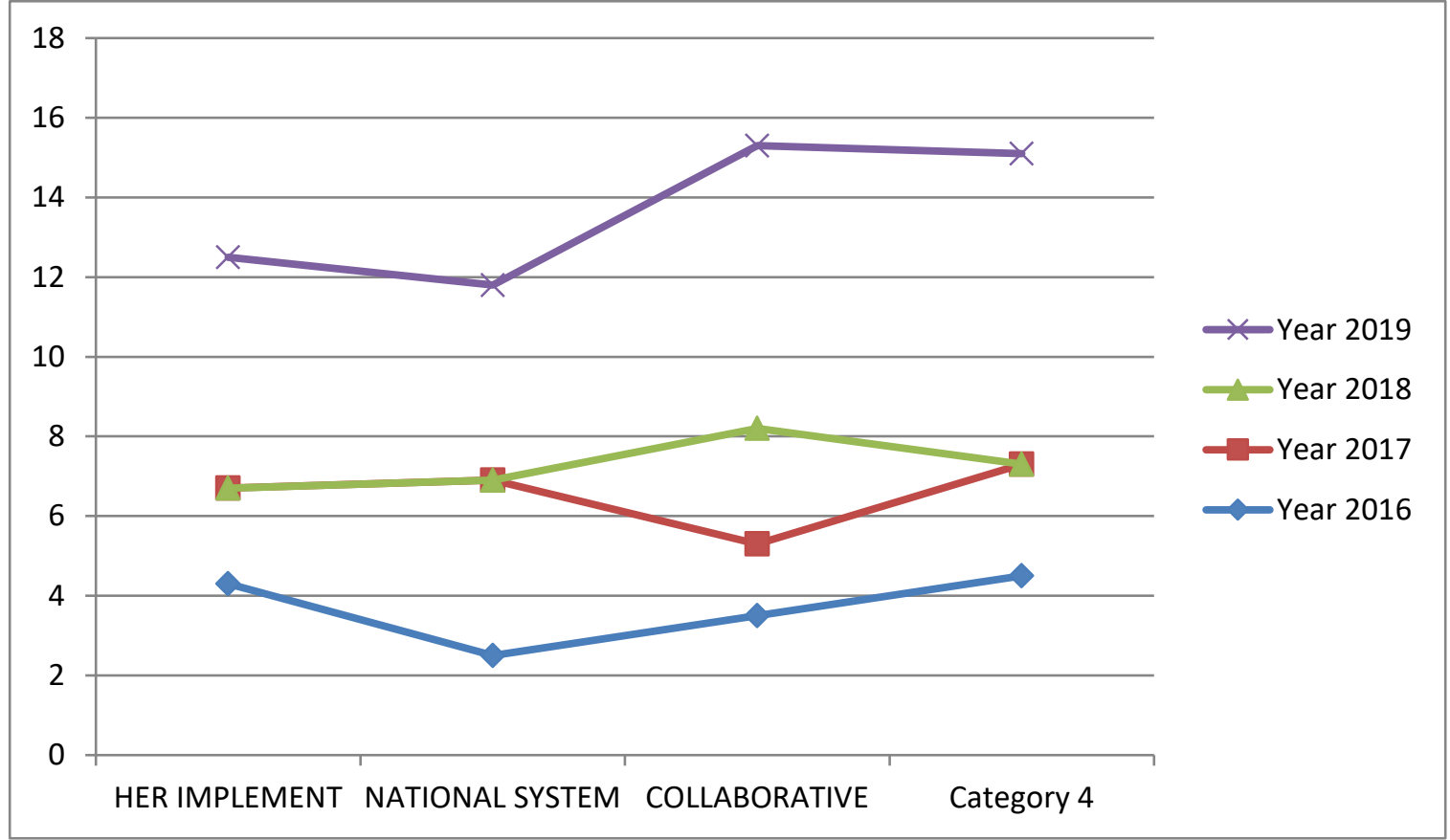

Source: The curriculum documents should reflect the intentions of the reform, be appropriate to students and useful to teachers. The research indicates that this approach can indeed produce achievement benefits. Particularly effective techniques include: Keeping questions at an appropriate level of difficulty; that is, at a level where most students can experience a high degree of success in answering

1. Investment in infrastructure and innovation are crucial drivers of economic growth and development. School infrastructure includes suitable spaces to learn for all students.

2. This is one of the most basic elements necessary to ensure access to education.

3. Facilities may be inadequate in many ways, including being over-crowded or dangerous or lacking in adequate learning facilities.

4. In addition, access to the Internet has become crucial to ensure equal access to information and knowledge, as well as to foster innovation and entrepreneurship.

Using information on student's levels of understanding to increase the pace of instruction whenever appropriate (There is a strong positive relationship between content covered and 
student achievement. Monitoring can alert teachers to situations where they can profitably pick up the instructional pace and thus cover more material.)

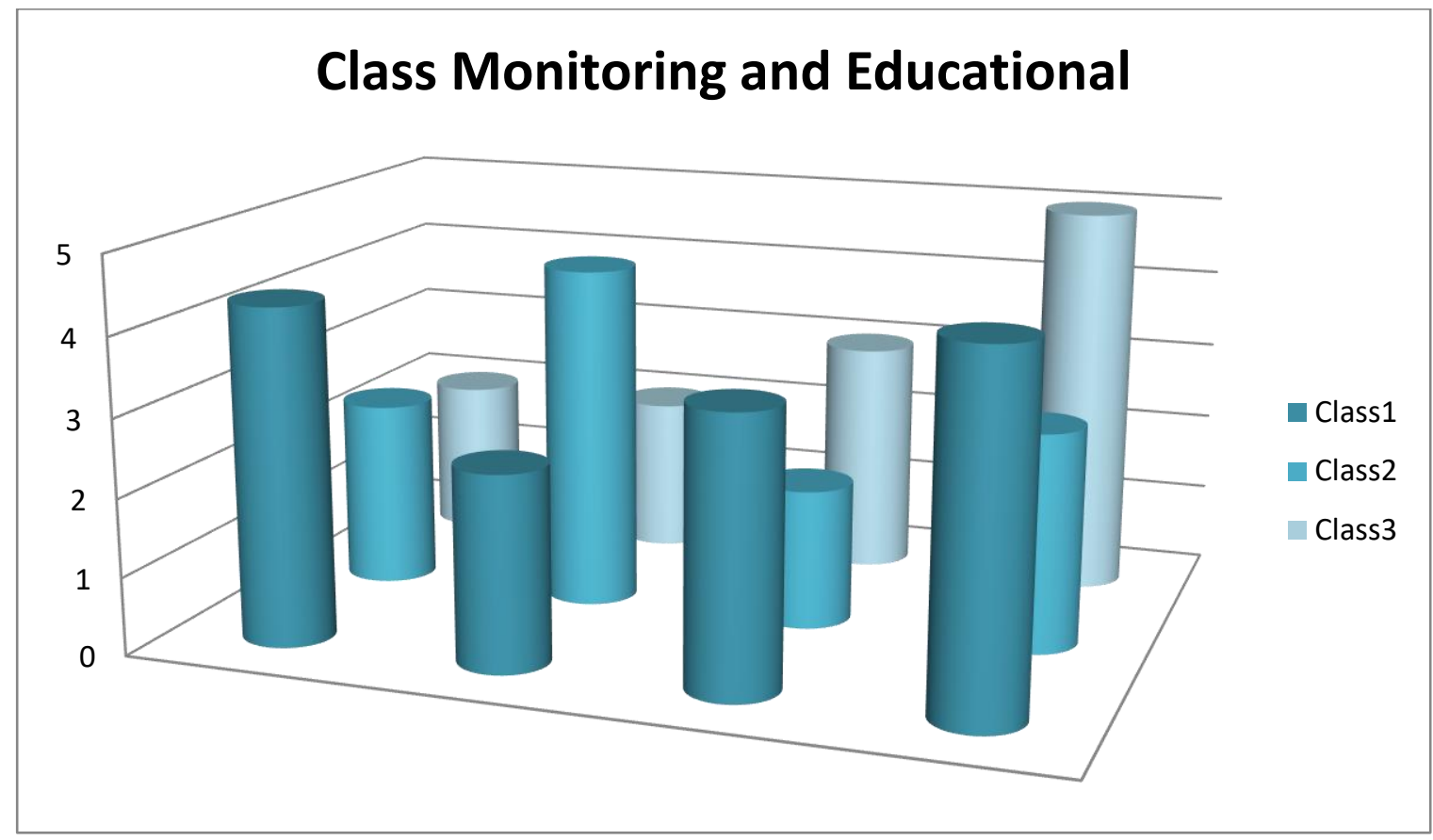

In addition to the development of Albania's physical infrastructure, the need to strengthen educational institutions through the development of the capacities of teachers and school leaders represents another crosscutting dimension that was evident throughout the EPR.

1. In each of the three policy domains, stakeholders highlighted the ways in which educational reforms and improvements hinged upon the development of improved infrastructure alongside new teaching and leadership competencies.

2. In the medium term, improve coordination of teacher preparation in universities, practical training, professional development and performance evaluation, including through harmonization of legislation.

3. You will use this document to see how much progress the student made from your last meeting. It's also a great resource to use at parent-teacher conferences, as well as it provides detailed information about the solutions and strategies that the student is, or will be using.

\section{How to Approach the Conference in your class}

Albania is committed to the global goals of sustainable development, gender equality, and education as a human right and a public good for all. However, social transformation is not a short-term Endeavour; it will require sustained effort in the medium and long-term towards 2030 
and beyond. Through effective engagement with local stakeholders and strategic development partnerships Albania will be well prepared to ensure inclusive and equitable quality education and lifelong learning, with wider benefits for society as a whole.

Here are a few tips on how you can approach the student-teacher conference in your class.

a) Plan it at a time when the other students are busy working in stations or small groups. This way you can take one table at a time to conference with.

b) The students at the "Conference" table that are waiting to meet with you can work on questions or concerns to bring to the meeting, or other busy work.

c) Make sure that you conference with the students in a place where you are far away from the other students, but close enough that you can keep an eye on everything.

d) Ideally, the best place would be at your desk or the reading table.

e) This saves time for me. Every conference is essentially a chance for ongoing formative assessment. As a result, I spend less time grading (especially leaving feedback on student work).

f) It allows me to thrive as an introverted teacher. I need this time one-on-one with students because the large crowd can feel exhausting.

g) Here are a few tips on how to hold a student-teacher conference in your classroom. Long gone are the days when only teachers had a say in their students' education.

h) Today's teachers are finding that when you give students the opportunity to have a say in their education, they are more likely to be motivated and engaged to learn.

i) Encourage your students to come to the meetings with questions and concerns that they may have. Ask them to write down a few notes to bring with them and give them the opportunity to share what they have to say

- Let students know ahead of time that you will be having student-teacher conferences with them. This gives them enough time to get prepared for it.

Conferences are a great way to get to know your students on a more personal level. The students will feel like they really know you, which will help increase their trust with you. Every chance that you get to meet with your students is an opportunity for assessment. This way you will have less time assessing at the end of the marking period, as well as a lot of notes to help you out when grading. 


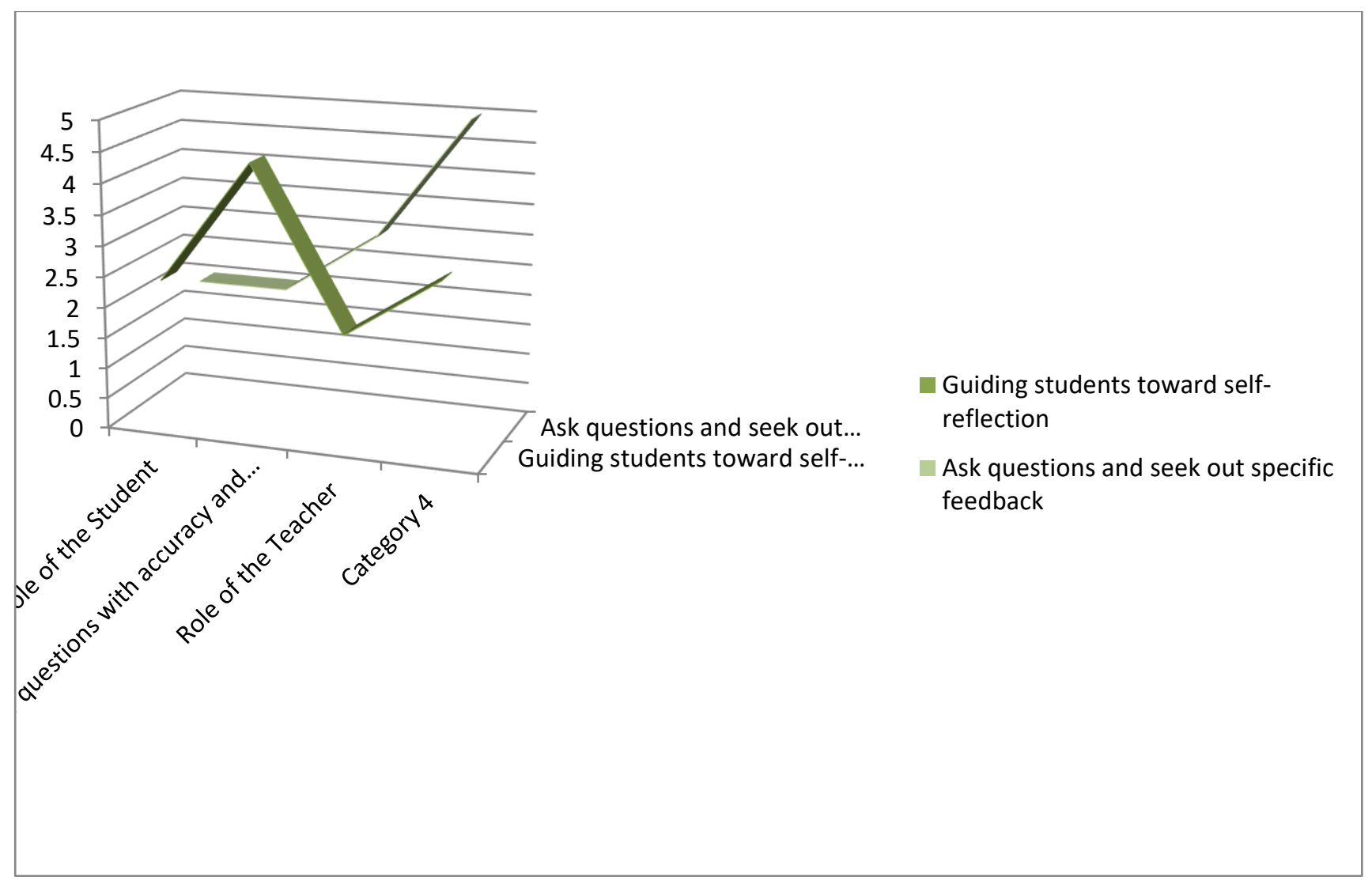

\section{HYPOTHESES AND THE AIM OF THIS PAPER RESEARCH}

The Republic of Albania stated that the UN-System in Albania could provide the following forms of support: know-how with respect to the methodological aspects of monitoring and evaluation; support in identifying gaps in terms of capacities; aid in the consolidation of capacities regarding the establishment of a monitoring system for the SDGs; and support with national processes to reach consensus on the targets. The Government of Albania also called for support in reaching 'a common understanding of linkages between the SDG outcome document and national strategic documents' as well as in aiding a 'dialogue on data requirements and statistical capacity needed for proposed SDG indicators.

a) Integrate student assessment components in the teacher training programmers, considering performance standards as well. Specifically, include in professional learning activities instruction in the use of data from formal and informal assessment for and of learning for purposes of instructional planning

b) Have systematic procedures for supervising and encouraging students while they work. Initiate more interactions with students during seatwork periods, rather than waiting for students to ask for help 
c) Through collaboration between MES and IED, conduct ongoing reviews of whether new textbooks are adequate for the purposes intended and provide additional information to schools regarding technology requirements related to the new curriculum.

d) Discuss with publishers the importance and possibility of increasing contextualization to Albania in textbooks, especially in math's and science

e) Have more substantive interactions with students during seatwork monitoring, stay taskoriented, and work through problems with students

f) Give extra time and attention to students they believe need extra help

g) Stress careful and consistent checking of assignments and require that these be turned in. Benefits for Students

a) Through collaboration between MES, IED, and teachers, prepare a guide to help educators identify what factors to consider in the selection of textbooks; for example, factors such as the previous experience of students, availability of other resources (including ICT), and students' language levels could be considered.

b) The student has a hand in identifying what he/she needs to work on

c) Students practice self-evaluation and self-reflection techniques

d) Because a student has a hand in it, he/she is more apt to care about the work towards the goal

e) It is not just something the teacher assigned.

f) Able to assess students in terms of motivation, attitude toward reading, ability to select and engage with texts, use of reading strategies, oral fluency, and narrative and expository text comprehension.

g) Do not invite the student in an ominous or formidable manner. 


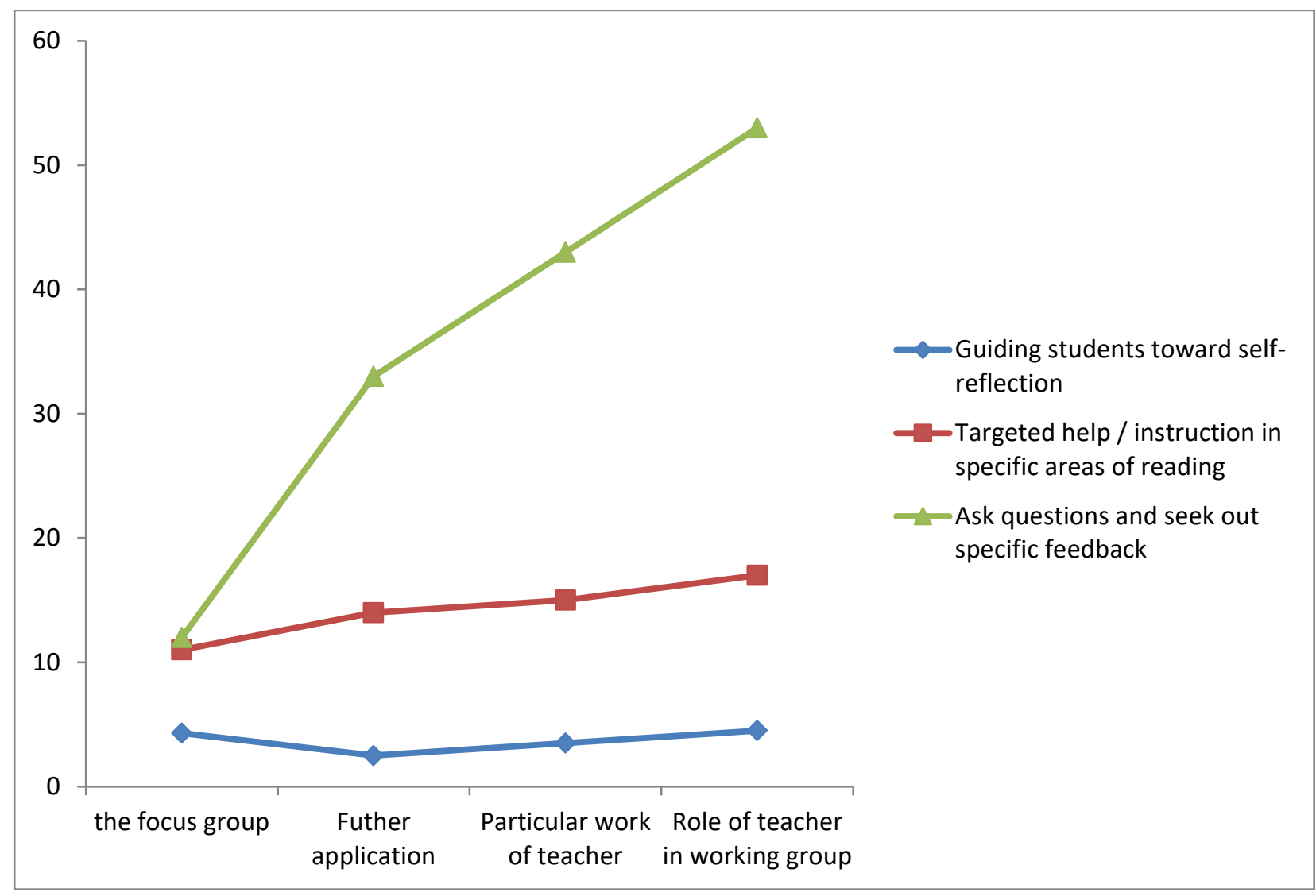

\section{CONCLUSIONS}

Strengthening capacities for monitoring and evaluation of educational reforms

One of the main purposes of monitoring and evaluation (M\&E) in education is to ensure that equitable and quality education is being provided to all of the population and at all levels. Quality education is a multi-dimensional concept that takes into account the quality aspects on input (human, material, and financial), process (teaching-learning and effective management practices), and outputs and outcomes (the learning outcomes and quality of results) (UNESCOIIEP, 2007). The better infrastructure as well as improve the coverage of education services in all geographical areas to help address the education needs of the rural populations and disadvantaged groups. Targeted support to higher education institutions would help to address critical needs in human resource development and strengthen institutional governance across the education system, including higher education particularly as it pertains to the education of future teachers and education professionals.

The use of homework assignments bears a significant and positive relationship to achievement when the homework is carefully monitored, as well as serving the function of increasing students' learning time. To address these key policy issues, the Government of Albania will need to pay significant attention to strengthening the monitoring and evaluation of the implementation of educational reforms. 
This demands that key indicators be defined, that a monitoring and evaluation framework be developed, that responsibilities are clearly assigned, and most importantly, that action is taken on the findings of monitoring and evaluation exercises.

An effective M\&E system can help not only governments, development partners and donors, but all those concerned with education and its quality and coverage. Homework confers the most beneficial results when assignments are:

a) Closely tied to the subject matter currently being studied in the classroom

b) Given frequently as a means of extending student practice time with new material Appropriate to the ability and maturity levels of students

c) Clearly understood by students and parents Monitored by parents; i.e., when parents are aware of what needs to be done and encourage homework completion Quickly checked and returned to students

d) Graded and commented on the research also indicates that homework which meets these criteria is positively related to student attitudes.

e) Students may say they don't like homework, but research shows that those who are assigned regular homework have more positive attitudes toward school, toward the particular subject areas in which homework is assigned, and toward homework itself, than students who have little or no homework.

\section{REFERENCES}

UNESCO and the Council of Europe Report . 2014. Inclusion from the start: Guidelines on inclusive early childhood care and education for Roma children. Paris: UNESCO. http://unesdoc.

unesco.org/images/0022/002275/227503e.pdf (Accessed 11 September 2016)

UNESCO-IIEP, 2016 http://www.iiep.unesco.org/en/our-expertise/monitoring-and-evaluation

Teacher pay for performance: Experimental evidence from the Project on Incentives in Teaching.

Santiago, P. and Benavides, F. 2009. Teacher Evaluation: A Conceptual Framework and examples of Country Practices. Paris, OECD Publishing. http://www.oecd.org/edu/school/44568106. pdf (Accessed 22 October 2015.)

Nashville, TN: National Center on Performance Incentives, Vanderbilt University

Vadahi, F. and Bilali, H. E. 2015. Approach of Albanian Non-Public Education with the European One.

European Scientific Journal, Vol. 11, No. 28, pp. 335-345. http://eujournal.

org/index.php/esj/article/viewFile/6394/6145 (Accessed 29 February 2016.)

National Association of State Boards of Education (NASBE)Study Group on Teacher Preparation, Retention, Evaluation, and Compensation (2011). Gearing Up: Creating a Systemic

World Bank. 2013. What Matters Most for Teacher Policies: A Framework Paper. 